\title{
Internal Friction of Ball Bearings at Very Low Temperatures
}

\author{
Jakub Sikorski - Witold Pawlowski* \\ Lodz University of Technology, Institute of Machine Tools and Production Engineering, Poland
}

Results of the study on the internal friction of steel ball bearings made of $\mathrm{X} 65 \mathrm{Cr} 14$ alloy and ceramic bearings made of zirconium oxide operating at temperatures lowered by liquid nitrogen down to $-195{ }^{\circ} \mathrm{C}$ are presented in this paper. Standard grease added by the manufacturer, while graphite and molybdenum disulphide powder were used for lubrication of the bearings during the measurements. Tests were also carried out to examine the performance of the bearings operating without lubrication. The power of bearing internal friction versus temperature was measured. The lowest bearing internal friction was observed for molybdenum disulphide, whose effective lubricating performance was verified for both types of ball bearings. Graphite powder was almost equally effective with the advantage of being suitable for use in machines that come into contact with food.

Keywords: rolling bearings, rolling resistance, lubrication, low temperatures

\section{Highlights}

- At very low temperatures $\left(-195^{\circ} \mathrm{C}\right)$ the type of lubrication used in the bearing is of much greater importance than the material of which the bearing is made.

- $\quad$ Steel bearings can be used in machines operating at very low temperatures provided that viscous lubricants are replaced with dry lubricants.

- $\quad$ The lowest bearing internal friction was observed for molybdenum disulphide, whose effective lubricating performance was verified for both steel and ceramic types of ball bearings.

- $\quad$ The performance of the bearings at low temperatures was supported by measuring the power of the internal friction as well as with the microscopic analyses of the surface structures of cooperating elements of the bearings.

\section{INTRODUCTION}

One of the most common assemblies in any machine is the bearing. It is also one of the most important ones as the failure-free operation of any equipment depends on its faultless functioning. The more complex the machine is, the more bearings it requires, which is why ensuring optimal operating conditions for each bearing in the machine is paramount. Several key factors affect the service life of the bearing. The most important one is the maintenance of proper lubrication.

Many studies on lubrication and lowering the coefficient of friction between cooperating machine parts have indicated lubricants expected to ensure reliable performance of bearings over a wide range of temperatures. Naturally, the first lubricants to be analysed were those added by the manufacturer. However, these substances fail to retain their properties within a broad spectrum of temperatures, especially when operating at low and very low temperatures. The increasing viscosity of the grease and subsequent formation of paraffinic microcrystals leads to a complete solidification of the lubricant and entrapment of the remaining liquid fraction in the crystal lattice of paraffin and wax [1] and [2]. The thin layer of lubricant in bearings undergoes elastohydrodynamic lubrication (EHL) for which the roughness of cooperation bearing surfaces is a significant factor [3]. The surface roughness, temperature, and lubrication methods as well as clearance size are also mutually dependent factors regarding friction and wear in composite plain bearings [4].

Solids exhibit greater stability over a wide temperature range. For this reason, the following study concentrated on the lubricating capacity of such substances, which reduce the coefficient of friction that are based on pure powder free of liquid fractions. Graphite and molybdenum disulphide are most frequently used for this purpose, while tungsten sulphide, graphite fluoride, tetrafluoroethylene, and certain polymers are resorted to less often [5] and [6].

The use of carbon in the form of graphite powder to lubricate cooperating machine parts has long been known and has been discussed extensively in the literature. However, the analyses of the behaviour of graphite as a lubricant were focused on high operating temperatures, with temperatures as high as $120{ }^{\circ} \mathrm{C}$ considered in some of the studies as low. Thermal conditions reported in the previous studies have ranged from ambient temperatures up to $550{ }^{\circ} \mathrm{C}$ [1], [5], [7] and [8].

Molybdenum disulphide is another well-known lubricant. Again, investigations of its lubricating performance when applied as a powder or a surface 
coating of cooperating parts have been carried out at temperatures varying from $20^{\circ} \mathrm{C}$ to $800{ }^{\circ} \mathrm{C}$ [9] to [13].

The behaviour of molybdenum disulphide and molybdenum disulphide and graphite composites bonded with polymer resins is also described. The effectiveness of these lubricating composites was tested to a temperature close to $-200{ }^{\circ} \mathrm{C}$ [14].

This article reports the analysis of the performance of steel and ceramic bearings operating under very low temperature conditions. The tests were carried out on ball bearings at temperatures lowered with liquid nitrogen to $-195^{\circ} \mathrm{C}$. Bearings lubricated with standard lubricant added by the manufacturer, graphite powder, and molybdenum disulphide powder were investigated. Attempts were also made to test the steel and ceramic bearings operating with no lubrication.

Depending on the manufacturer, operation limit temperatures in the range of $-30{ }^{\circ} \mathrm{C}$ to $-80{ }^{\circ} \mathrm{C}$ are recommended for commercially available rolling bearings and lubricants [15]. The following study is to enhance the current understanding of how bearings and lubricants behave at very low temperatures, which could be useful in the design of new generation robots for exploration of space and nearby planets in the solar system.

\section{DESCRIPTION OF THE EXPERIMENT SETUP}

The most important element of the test bench shown in Fig. 1 is a low-temperature chamber, inside which the ball bearing (1) is mounted on the aluminium frame (2) with an aluminium clamping ring (3) fastened to the frame with two bolts (4). Furthermore, a copper tube is included in the frame (5), inside of which a resistance detector of temperature (6) has been placed. The purpose of the tube is to improve heat transfer to the detector glued inside one of the tube pieces with silver-based thermal paste.

The drive system of the bearing is comprised of a high-speed DC motor (7), a clutch (8) which transmits torque to the drive shaft (9) at the end of which the bearing is installed. The point of using a DC motor was to significantly simplify the procedure for measuring the power of the bearing internal friction. Two neodymium magnets (10) are embedded in the shaft openings, cooperating with a Hall effect sensor (11) used for precise measurement of the rotational speed of the bearing. The entire mechanical system is encased in a two-piece thermal cover (12) made of extruded polystyrene foam and fitted with a sight glass (13) at its front to enable observation of the bearing during the test. A hole at the top of the cover allows liquid nitrogen to be supplied to cool the bearing.

The measurement setup illustrated in Fig. 2 consists of a low-temperature chamber (1) into which liquid nitrogen from a dewar (2) is supplied through a PTFE tube capable of withstanding low temperatures. The electric motor is powered with a laboratory power supply (3), and its rotational speed is measured by a frequency meter (4) receiving impulses from the Hall effect detector. Other elements include universal meters to measure the temperature detector resistance (5) and to control voltage drops across the power cords (6). The last device connected to the laboratory power supply is an oscilloscope (7) that additionally monitors potential voltage surges on the electric motor. The data from the power supply, frequency meter, and resistance meter are recorded on a laptop computer (8).
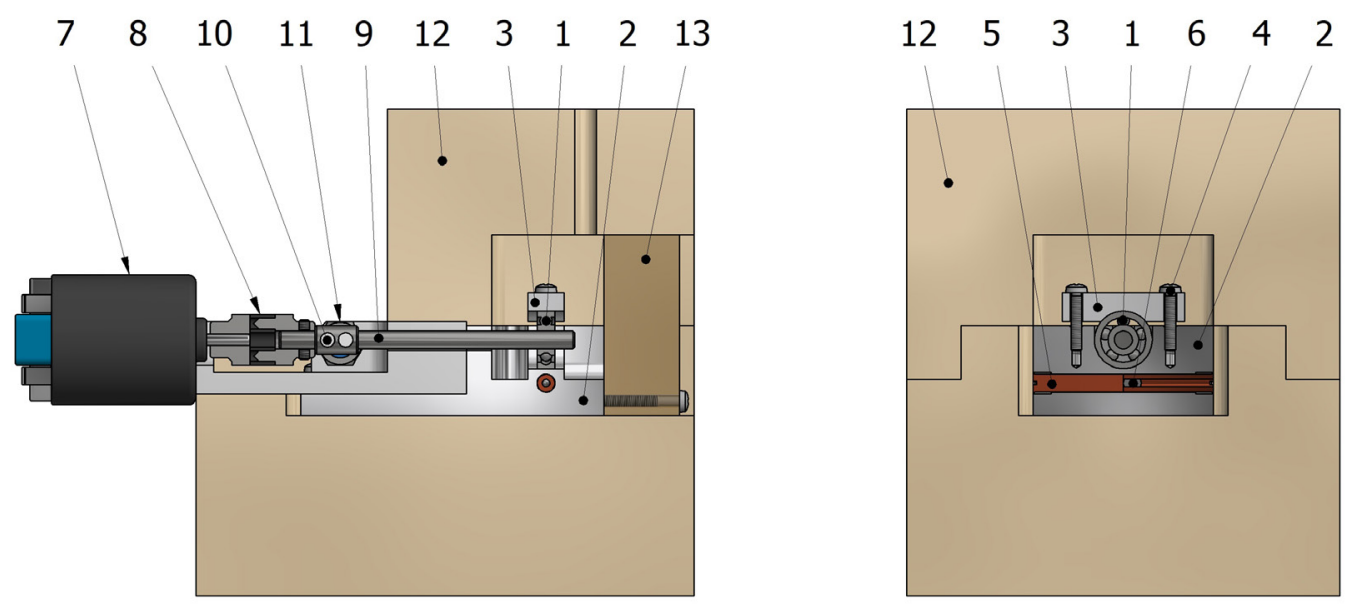

Fig. 1. Front and side section view of the low-temperature chamber 


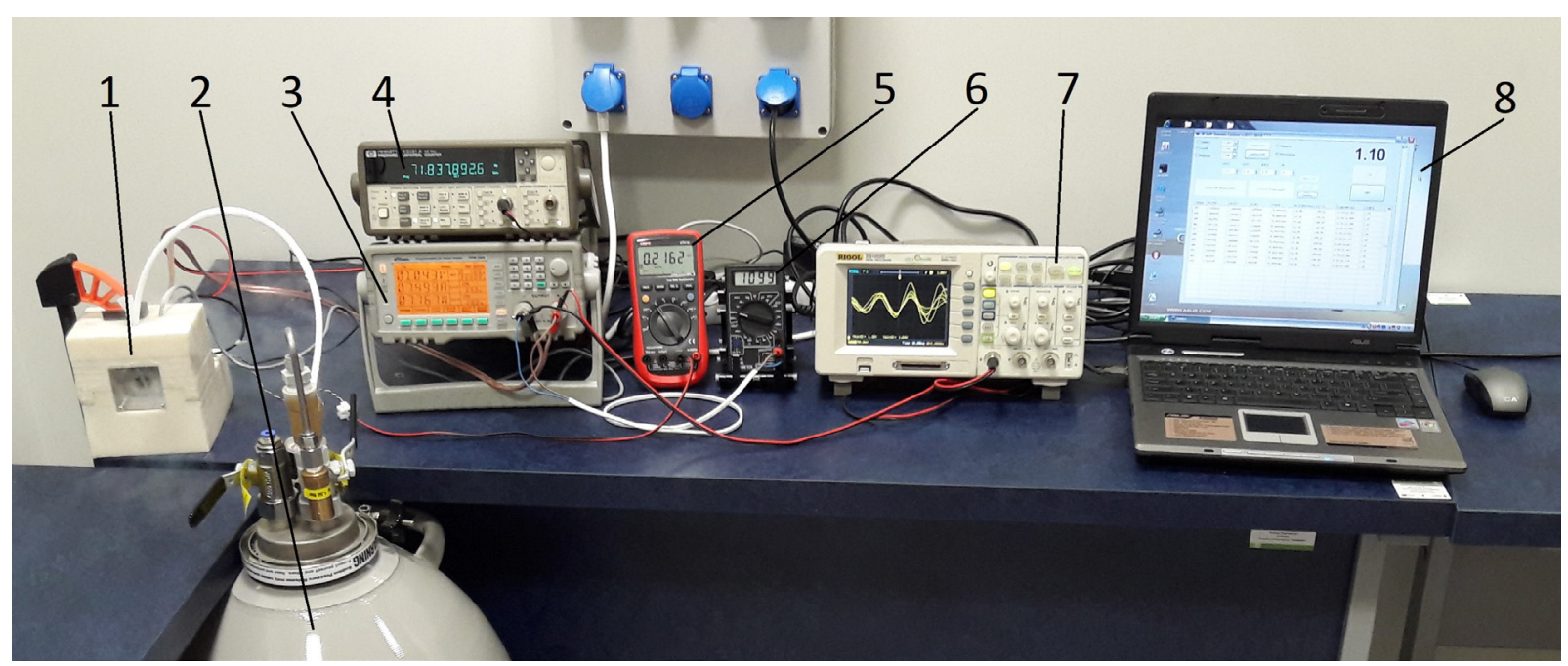

Fig. 2. Low-temperature chamber with measuring equipment

\section{RESEARCH METHODOLOGY}

Friction is a prevalent physical phenomenon. It occurs whenever an object is in motion and strives to counteract it. In machines, two main types of friction can be identified: kinetic or sliding friction in bearings and sliding joints, and rolling friction in all types of rolling bearings. In the case of rolling objects, surface deformation is always observed; therefore, the harder the material of which the bearing is made, the smaller the contact surface of the bearing elements, which may consequently result in less friction.

Friction between the balls of the bearing and its inner and outer races generates friction torque that counteracts the rotation of the bearing. The torque, combined with information on the rotational speed of the shaft on which the bearing is mounted, enables calculating the power required to drive the rotating bearing. Based on the above information, it was concluded that the electric power supplied to the electric motor that puts the bearing into rotational motion reflects the bearing internal friction.

The first step in getting ready for determining the bearing internal friction was to determine the power of resistance to movement of the drive system itself. For this purpose, the power consumption of the drive motor and power supply cords was analysed. The laboratory power supply used in the study allows the user to control the voltage and current supplied to the motor with a computer, which renders the procedure of supplying power to the motor entirely reproducible. The laboratory power supply also allows the user to monitor voltage drops on the power cords with a second pair of cords. A schematic diagram in Fig. 3 shows the correct connection of the entire system. OFC $4 \mathrm{~N}$ oxygen-free copper cables with a crosssection area of $4 \mathrm{~mm}^{2}$ were used to further limit influence of resistance from the power cords. The objective was to minimize cable heat-up during operation and maintain consistent resistance during subsequent measurements. The values of the power of the electric motor and cords thus obtained were subtracted from the total power of the entire setup (with bearing) to determine the power lost during the operation of the bearing.

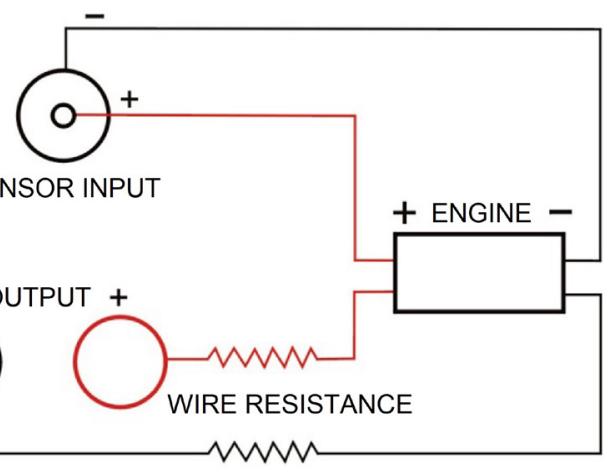

Fig. 3. Schematic diagram of the laboratory power supply connection

Before the measurements, each bearing was submitted to the following procedure to normalize the testing parameters. For all the measurements, $5 \mathrm{~mm} \times$ $16 \mathrm{~mm} \times 5 \mathrm{~mm}$ type 625 ball bearings without seals were used. After being installed on the drive shaft, the 
bearing was placed in the frame and secured with the clamping ring bolts tightened in the same reproducible manner for each test.

Next, the drive system of the bearing was run for about an hour so that, at a speed of about 30,000 rpm, the bearing would complete 2,000,000 revolutions, which was recorded by a frequency meter. The purpose was to remove excess lubricant from the bearing and to obtain consistent and reproducible measurement results. The preliminary 2,000,000 revolutions proved to be particularly meaningful for bearings lubricated with viscous grease, as is evident in the graph below (Fig. 4) illustrating the attempt to run measurements on a newly installed bearing. Apparently, an excess of the lubricant caused the bearing to seize up at a temperature of $-14^{\circ} \mathrm{C}$ due to the lubricant thickening. The lubricant increasing its viscosity also results in the increase of the power required to drive the bearing with higher movement resistance which in turn causes temporary warming of the bearing.

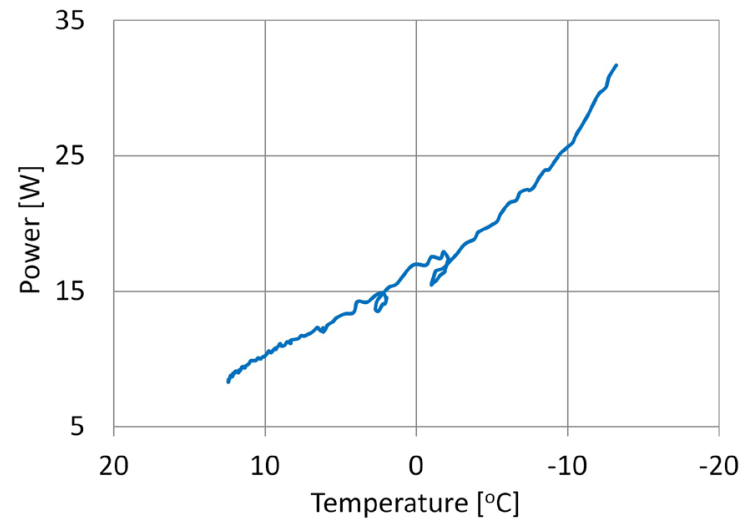

Fig. 4. Power of the steel bearing internal friction immediately upon mounting

All experiments (40 per each bearing type) were performed according to the following procedure:

- running the bearing at ambient temperature for $10 \min (60,000$ rotations or 130,000 rotations respectively) in order to stabilize the initial conditions of the measurement,

- closing the low-temperature chamber and the moisture removal by the nitrogen insufflation,

- the measurement procedure of gradual cooling the bearing to $-195^{\circ} \mathrm{C}$ lasting $8 \mathrm{~min}$ to $22 \mathrm{~min}$,

- opening the chamber and gradual warming the still rotating bearing $(60 \mathrm{~min})$.

During each cycle of measurements of the bearing internal friction, the following data were collected: the values of voltage, electric current, and power supplied to the motor recorded by the laboratory power supply, the drive shaft rotational speed by the Hall effect sensor connected to the frequency meter, and the resistance of the temperature sensor read by the universal meter. All the above measuring instruments were connected to the computer in which, with the aid of proprietary software, the data was logged at a speed of about 80 rows per minute and, in the case of temperature, converted from electrical resistance.

Based on the results of the preliminary measurements, it was concluded that to ensure the most consistent results, the bearings should be cooled down at the slowest rate possible. For this reason, the results of measurement cycles of less than 8 minutes were disregarded. In the next section, examples of charts that provide information about the power of the analysed steel and ceramic bearings' internal friction are presented. The charts were produced based on data sets with 600 to 1,700 measurement data rows.

\section{ANALYSIS OF THE RESULTS}

The experiments comprised 80 measurement cycles performed for two types of bearings. Based on the analysis of the test results, the maximum dispersion of the measurement values for each bearing type was determined to be max. $7 \%$. The graphs below present the most representative measurements of the power of bearing internal friction versus temperature. The first chart (Fig. 5) illustrates the results of measurements of the power of the internal friction of a steel bearing made of $\mathrm{X} 65 \mathrm{Cr} 14$ alloy mounted on a drive shaft rotating at a speed of $6,000 \mathrm{rpm}$. The choice of stainless steel bearings (X65Cr14) was caused by the resistance to possible corrosion. That corrosion could be initiated by moisture condensing during the heating phase of the test rig when the low-temperature chamber is open. The effect of the corrosion could have introduced additional errors during the power measurements. During the preliminary tests, the bearing operated with the lubricant added by the manufacturer. The grease was then removed, and attempts were made to test the performance of the bearing completely clean of lubrication. Unfortunately, the steel bearings run without any lubricant would fail after only a few hours of testing. The last one to be tested was a bearing in which the standard grease was replaced with molybdenum disulphide powder.

With standard grease, a gradual increase in the power of the bearing internal friction is clearly evident until the thickening lubricant was almost completely removed from the race where the bearing balls rolled. For lubricant-free and molybdenum disulphide measurements, the graphs show almost linear trends 
over the entire temperature range. This is explained by the powder lubricant being non-sensitive to the decrease in temperature, whereas a slight increase in the power consumed by the bearing can most probably be attributed to the shrinkage of the aluminium housing, which led to additional clamping of the outer bearing race.

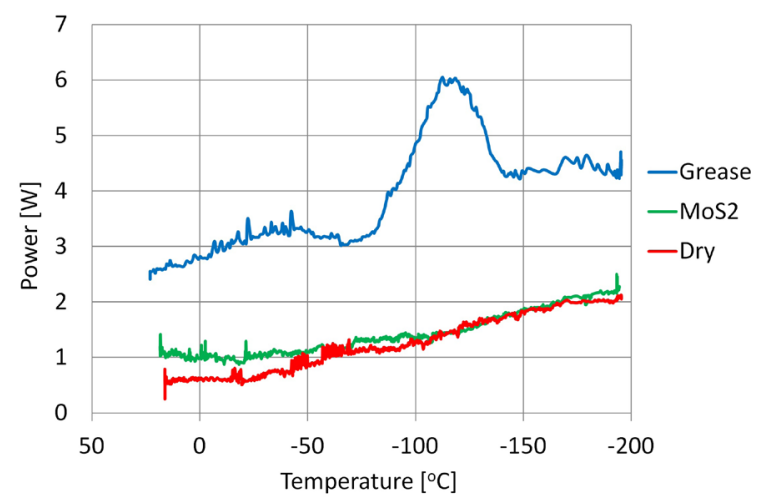

Fig. 5. Power of the steel bearing internal friction, 6,000 rpm

The graph (Fig. 6) shows the internal friction of a steel bearing mounted on a drive shaft rotating at a speed of $13,000 \mathrm{rpm}$. The same lubrication parameters as for the speed of 6,000 rpm were used for the measurements. The higher rotational speed further exposed inadequate properties of the viscous grease and confirmed the low internal friction values produced by the bearing lubricated with molybdenum disulphide. Furthermore, it has been successfully demonstrated that for both rotational speeds the steel bearing is capable of performing its function even at $-195{ }^{\circ} \mathrm{C}$, although the issue of selecting the most appropriate lubricant remains of utmost importance.

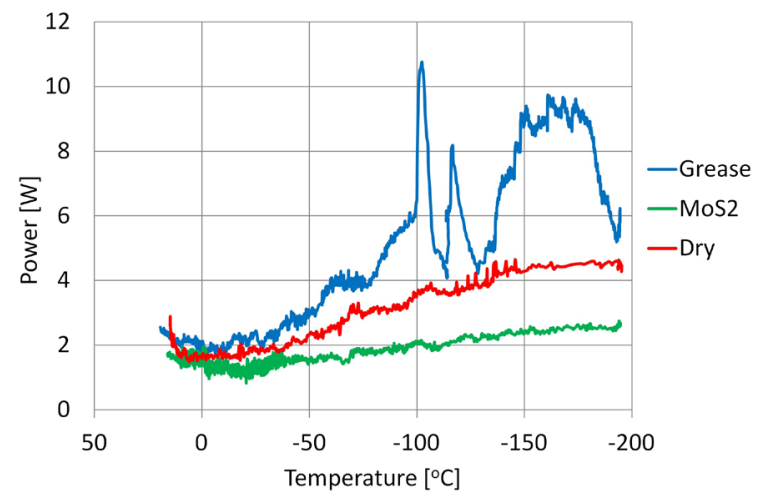

Fig. 6. Power of the steel bearing internal friction, 13,000 rpm

The graph in Fig. 7 presents the internal friction of a zirconium oxide bearing mounted on a shaft rotating at a speed of $6,000 \mathrm{rpm}$. The full ceramic bearing (both races and balls) is commercially supplied with no lubricant added and has been designed to operate as such. The subsequent tests were carried out with graphite and molybdenum disulphide powder lubrication. As the chart clearly shows for all the variants, the bearing internal friction was low and increased linearly starting at $-50{ }^{\circ} \mathrm{C}$ as the temperature recorded inside the low-temperature chamber was decreasing. Again, the increase in the power consumed by the bearing was probably caused by the shrinkage of the aluminium housing, which resulted in additional clamping of the outer race of the bearing. Slightly higher values of the power of internal friction observed for the ceramic bearing could have been caused by a smaller predetermined internal clearance than for the steel bearing.

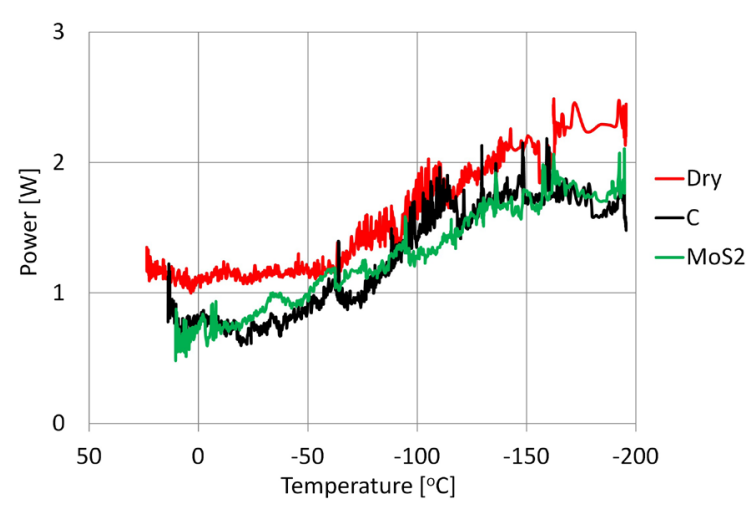

Fig. 7. Power of the ceramic bearing internal friction, $6,000 \mathrm{rpm}$

The graph (Fig. 8) shows the internal friction of a ceramic bearing mounted on a shaft rotating at a speed of 13,000 rpm. As is evident, power trends for the non-lubricated and graphite powder lubricated bearings are similar to those observed for 6,000 rpm. The values of the power of the bearing internal friction are only proportionately higher relative to the higher rotational speed of the drive shaft. When lubricated with molybdenum disulphide powder, the bearing resistance remained at virtually the same level as in the previous chart. This further corroborates the claim that the increase in internal friction was caused only by the change in the bearing dimensions resulting from a temperature decrease to $-195{ }^{\circ} \mathrm{C}$. As in the previous charts, also here, for all the cases, the bearing internal friction increased linearly with decreasing temperature, starting at about $-20^{\circ} \mathrm{C}$. 


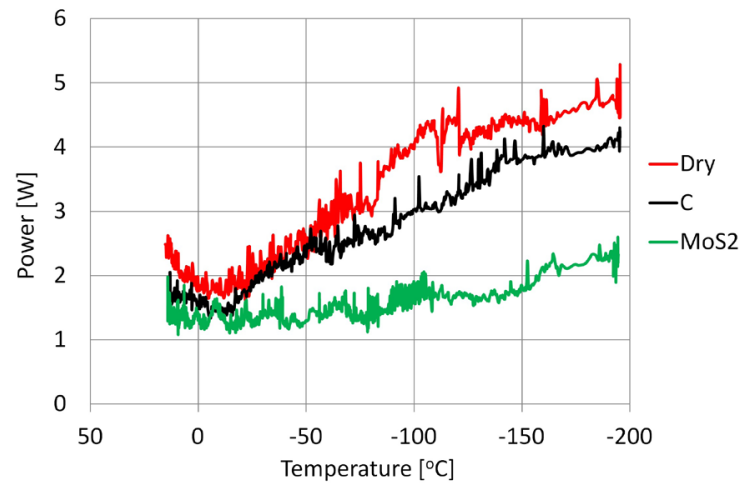

Fig. 8. Power of the ceramic bearing internal friction, $13,000 \mathrm{rpm}$

\section{ANALYSIS OF THE CONDITION OF THE BEARINGS}

Having completed the measurements, an attempt was made to inspect the mechanical condition of the bearings that had been tested at the bench. For this purpose, microscope images of new bearing balls and balls of the bearings used in the tests at the test bench were captured.

Fig. 9 shows an image of a ball of a new steel bearing. The visible irregularities are due to the machining of the ball by the bearing manufacturer. A large number of surface scratches and pits are evident. For this reason, a lubricant is required for proper operation of steel bearings to facilitate interaction between the ball and the bearing races. The dark spots in the image are a residue of the grease added by the manufacturer.

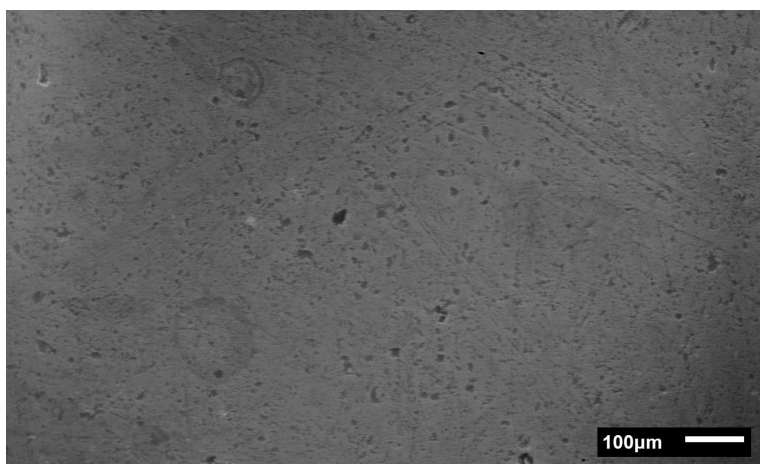

Fig. 9. Surface of the ball of a new steel bearing

The image (Fig. 10) is a photograph of a ball of a steel bearing run in the most difficult conditions, i.e., with no lubrication. Areas are visible where the material has been torn off the surface of the ball due to friction between the bearing assembly parts, significantly impairing the smoothness of the interacting surfaces. A high rate of growth in the number of such defects results in a global increase in the bearing internal friction and thus in elevated temperatures of the rolling parts, which further accelerates the process of the bearing degradation. This is why it is so crucial that lubricant is used in steel bearings as it reduces friction and improves heat dissipation from the areas of the bearing under the greatest loads. Only a few hours of operation resulted in the bearing failure due to deterioration of the ball and race surfaces.

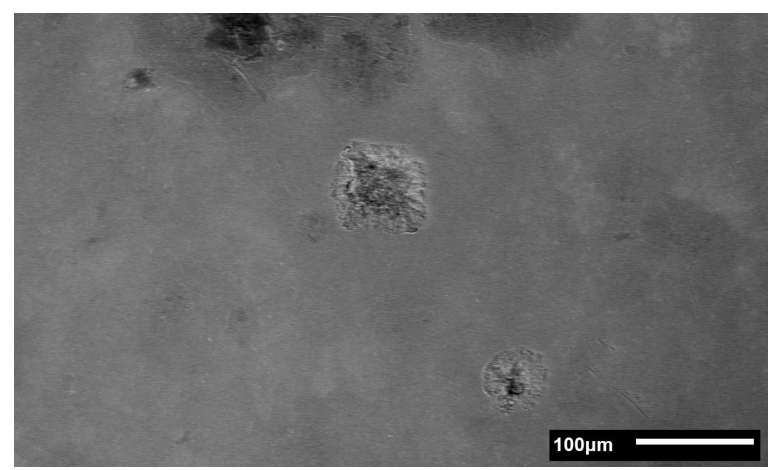

Fig. 10. Surface of the ball of a steel bearing after the tests

In Fig. 11, an image of a ball of a new ceramic bearing is shown. Clearly, the surface is much smoother than in the case of the steel bearing. The only few irregularities noticeable come from the machining of the ball by the bearing manufacturer. To reveal any further surface irregularities, it was necessary to take a photograph with the magnification 20 times higher than required for the steel bearing. The high degree of smoothness and the high level of the material hardness render ceramic bearings capable of operating without additional lubrication.

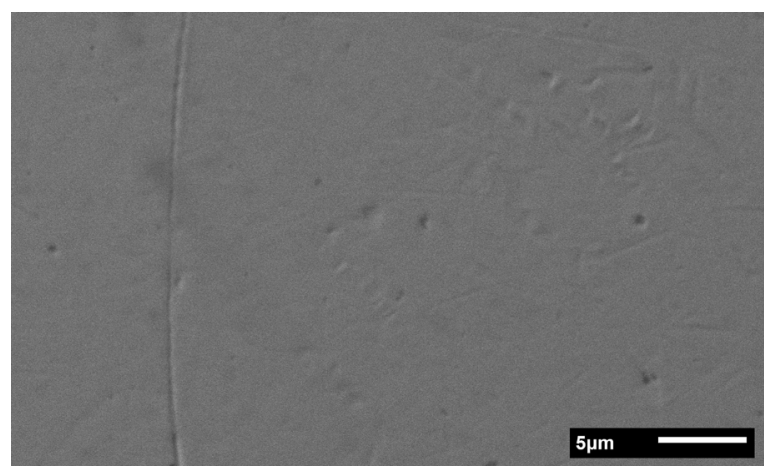

Fig. 11. Surface of the ball of a new ceramic bearing

The image (Fig. 12) shows a ceramic bearing ball after the measurements of the bearing internal friction. During all cycles of measurement, the ceramic bearing completed 7,000,000 revolutions at the bench, 
operating with lubrication by molybdenum disulphide powder without grease. The surface of the ball shows minor signs of wear, but it is essential to remember that the size of the scratches and damaged areas is minute. Molybdenum disulphide is also visible in the photograph, filling all minor damage areas and improving the overall smoothness of the ball surface. The molybdenum disulphide powder may have been removed from larger scratches during the ball cleaning process prior to microscopic imaging.

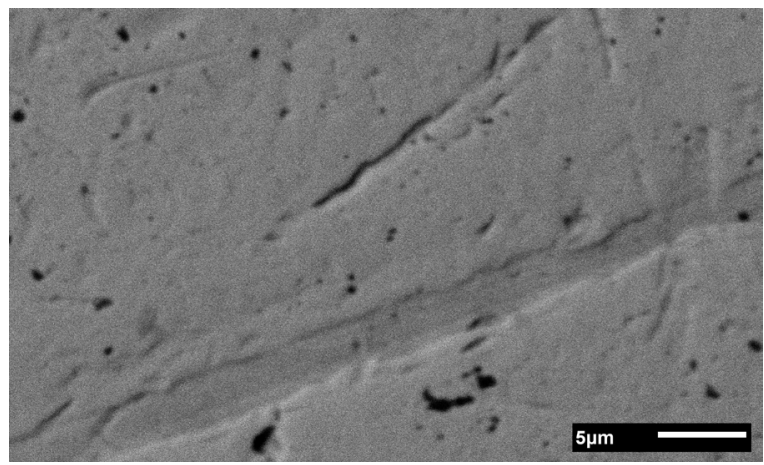

Fig. 12. Surface of the ball of a ceramic bearing after the test

During all performed tests, constantly growing power consumption of the bearing due to its wear was not observed. Both measurements of the power of bearing initial friction as well as microscopic images of the bearing balls subjected to the examinations indicate that the accelerated structural wear of tested bearing elements at low temperatures does not occur significantly.

\section{CONCLUSIONS}

Based on the performed measurements, it has been found that the type of lubrication used in the bearing is of much greater importance than the material of which the bearing is made. Contrary to the general opinion, steel bearings can be used in machines operating at very low temperatures provided that viscous lubricants are replaced with dry lubricants. The virtually linear graphs indicate that operation of steel and ceramic bearings should be possible and reliable even at temperatures lower than $-195^{\circ} \mathrm{C}$.

The lowest bearing internal friction was observed for molybdenum disulphide, whose effective lubricating performance was verified for both types of ball bearings. Furthermore, its properties remained unaffected throughout all the measurement cycles performed on bearings lubricated in this manner. Graphite powder was almost equally effective with the added advantage of being suitable for use in machines that come into contact with food.

Due to the design of the test bench, the thermal expansion of individual materials in contact with the studied bearings was taken into account in the tests. The increase in power with decreasing temperature is certainly due to the shrinkage of the aluminium frame; however, the increase in power due to the shrinkage of the bearing itself cannot be ruled out on that stage of research. These issues, as well as the interaction of the bearings with materials such as aluminium and titanium alloys used as a construction material for shafts and hub assemblies, will be the focus of future research.

\section{REFERENCES}

[1] Mortier, R.M., Orszulik, S.T. (eds.) (1992). Chemistry and Technology of Lubricants. Springer Science + Business Media, New York.

[2] Wie, B. (2015). Recent advances on mitigating wax problem using polymeric wax crystal modifier. Journal of Petroleum Exploration and Production Technology, vol. 5, p. 391-401, D0I:10.1007/s13202-014-0146-6.

[3] Yang, X., Li, Y., Liu, G., Wang, J. (2019). Effect of surface roughness on elastohydrodynamic lubrication performance of cylindrical roller bearing. Technical Gazette - Tehnički vjesnik, vol. 26, no. 3, p. 710-721, Dol:10.17559/TV20190104091451.

[4] Miler, D., Škec, S., Katana, B., Žeželj, D. (2019). An experimental study of composite plain bearings: The influence of clearance on friction coefficient and temperature. Strojniški vestnik - Journal of Mechanical Engineering, vol. 65, no. 10, p. 547-556, Dol:10.5545/sv-jme.2019.6108.

[5] Sliney, H.E. (1991). Solid Lubricants. NASA Technical Memorandum, NASA, Cleveland.

[6] Miyoshi, K. (1999). Considerations in vacuum tribology (adhesion, friction, wear, and solid lubrication in vacuum). Tribology International, vol. 32, no. 11, p. 605-616, D0I:10.1016/S0301-679X(99)00093-6.

[7] Peterson, M.B., Johnson, R.L. (1956). Friction studies of graphite and mixtures of graphite with several metallic oxides and salts at temperatures to $1000^{\circ} \mathrm{F}$. NASA Technical Notes, NASA, Cleveland.

[8] Savage, R.H. (1948). Graphite Lubrication. Journal of Applied Physics, vol. 19, no. 1, DOl:10.1063/1.1697867.

[9] Johnson, V.R., Vaughn, G.W. (1956). Investigation of the mechanism of $\mathrm{MoS}_{2}$ lubrication in vacuum. Journal of Applied Physics, vol. 27, no. 10, p. 1173-1179, DOI:10.1063/1.1722224.

[10] Khare, H.S., Burris, D.L. (2013). The effects of environmental water and oxygen on the temperature-dependent friction of sputtered molybdenum disulfide. Tribology Letters, vol. 52, p. 485-493, DOI:10.1007/s11249-013-0233-8.

[11] Kubart, T., Polcar, T., Kopecký, L., Novák, R., Novákova, D. (2005). Temperature dependence of tribological properties of $\mathrm{MoS}_{2}$ and $\mathrm{MoSe}_{2}$ coatings. Surface and Coatings 
Technology, vol. 193, no. 1-3, p. 230-233, D0l:10.1016/j. surfcoat.2004.08.146.

[12] Muratore, C., Voevodin, A.A. (2006). Molybdenum disulfide as a lubricant and catalyst in adaptive nanocomposite coatings. Surface and Coatings Technology, vol. 201, no. 7, p. 41254130, D0I:10.1016/j.surfcoat.2006.08.014.

[13] Khare, H.S., Burris, D.L. (2014). Surface and subsurface contributions of oxidation and moisture to room temperature friction of molybdenum disulfide. Tribology Letters, vol. 53, p. 329-336, D0I:10.1007/s11249-013-0273-0.
[14] Yukhno, T.P., Vvedensky, Y.V., Sentyurikhina, L.N. (2001). Low temperature investigations on frictional behavior and wear resistance of solid lubricant coatings. Tribology International, vol. 34, no. 4, p. 293-298, D0l:10.1016/ S0301-679X(01)00013-5.

[15] Diemand, D. (1990). Lubricants at low temperatures. Cold Regions Technical Digest, no. 90, USA Cold Regions Research and Engineering Laboratory, Hanover. 